\title{
Effects of increasing success and failure on perceived information quality ${ }^{\prime}$
}

SIEGFRIED STREUFERT, DEPARTMENT OF PSYCHOLOGY, PURDUE UNIVERSITY, Lafayette, Ind. 47907, AND CARL H. CASTORE, DEPARTMENT OF PSYCHOLOGY, RUTGERSTHE STATE UNIVERSITY, New Brunswick, New Jersey

The effect of experimentally-induced success and failure in a complex decision-making task on subjective estimates of information quality was obtained for information relevant to $\mathrm{Ss}^{\circ}$ own decision-making area and that of a marginal group member. It was found that quality initially is perceived to improve. Estimates of quality for success and failure conditions do not differ until success and failure levels are quite high. Once high levels of success are reached, $S$ s in the success condition consider information was further improving, while $S$ s in failure conditions maintain previous perceptions. The implications of this result for complexity theory are considered.

Considerable research has been concerned with the effect of information on human behavior. Implicitly some of the work has dealt directly with the effect of information quality. For instance, from the view of information theory (e.g., Attneave, 1959), an amount of information that reduces uncertainty to a particular degree can be viewed as possessing "quality." In other words, information communicating a bite of information would be of higher quality than information communicating a bit of information. Similarly, information levels that produce optimal integrative information processing characteristics (Driver \& Streufert, 1966; Schroder, Driver, \& Streufert, 1967) might be seen as possessing greater quality than information levels that produce less than optimal integrative information processing.

Such conceptualizations of information quality, although based on subject performance, are experimenter defined. What, however, is the S's perception of information quality? A partial attempt to answer that question is made in this paper.

Streufert \& Streufert (1968) have recently demonstrated that groups of Ss exposed to increasing failure conditions attribute as much cause to their own decisions as they credit to an opponent's decisions when they are asked to explain the basis of their present (failure) situation. These estimates of causality do not change over different failure levels. However, Ss in increasing success conditions tend to attribute more and more causality to their own decisions.

If attributions of quality to information would follow similar patterns, then one might expect that under high success conditions, Ss would consider information to be of higher quality than they would under low success, or low and high failure conditions. If, on the other hand, information quality perceptions are structurally determined (Driver \& Streufert, 1966; Schroder et al, 1967), no differences between success and failure conditions should emerge.

In this research the effect of increasing failure and increasing success on perceived information quality is investigated. In addition to estimates of information quality concerning the S's own decision area, estimates of quality for information relevant to the decisions of a marginal group member are obtained.

Subjects and Task. Thirty-six paid undergraduate male volunteers from an eastern state university were placed into 18 two-man decision-making teams. The Ss were instructed to act as equal rank decision makers in a simulated internation game situation. (The setting is discussed in detail in Streufert, Kliger, Castore, \& Driver, 1967.) Each team was given the task of making military, economic, intelligence, and negotiation decisions regarding an international conflict situation with some Vietnam characteristics. Teams were told that they were playing a game against another team which supposedly had been instructed to oppose them. All functions of the "enemy team" were pre-programmed and performed by the Es. Consequences of the
Ss' decisions as determined by the Es (see below) were fed back to the Ss. Eighteen Ss were placed into the "failure" condition, and 18 others into the "success" condition. Methods of inducing failure or success are described below.

All dyads participated in the game for seven consecutive 30-min periods To avoid an end effect, teams were not told which period would be the last. During each period, they received seven written messages, spaced in equal time intervals. Although the specific content of the messages differed, depending on the partucular actions the group had taken, the general content and the failure-success components of the messages were held constant for all groups. During the first period, one out of seven messages reported a failure (or success), while all other messages were neutral in content. During the second period, two out of seven messages reported failure (or success), and so forth, so that during the seventh playing period all messages reported failure (or success). In other words, the proportion of messages communicating failure (or success) varied from $1 / 7$ in the first period of the game to $7 / 7$ in the seventh (last) period.

The Ss were told that they had responsibility to make military, economic, and intelligence decisions. At the beginning of the game they were introduced to another team member who would make negotiation decisions. The Ss never saw this person again and contact with this "marginal" group member was maintained only through programmed messages about the negotiations.

Data Collection. After each 30-min game period, Ss were given a number of forms to fill out. One of these included a series of seven-point scales with the following instructions:

Indicate below your opinion as to the quality of the information you received during the last period in both listed areas.

Type of information:

Tactical/Economic/Intelligence

Negotiation

$$
\text { Very high quality - Very low quality }
$$

Results. A three-way mixed design analysis of variance was performed on the data. Main effects for success-failure (A, between, $F=0.70$ ) and for own vs marginal member's decision area (C, within, $F=0.60$ ) were nonsignificant. The main effect for periods of increasing success or failure proportions $(B$, within, $F=$ $17.02, \mathrm{p}<.01)$ was significant. Interaction effects $A$ by $B(F=$ $12.44, \mathrm{p}<.01)$ and $\mathrm{B}$ by $\mathrm{C}(\mathrm{F}=4.36, \mathrm{p}<.01)$ were significant. Interactions $A$ by $C(F=2.18)$ and $A$ by $B$ by $C(F=1.73)$ were not significant.

The results of this experiment point toward the importance of increasing success and failure for the perception of information quality. Both the main effect for periods of increasing success and failure proportions and its interaction effects with decision areas, and particularly with experimentally-induced failure vs induced success, show significance. In line with this finding, further analysis by the post hoc Newman-Keuls method of the effects of increasing failure or increasing success proportions on groups exposed to failure or success were made (based on the A by $B$ interaction). For this purpose, data from decision areas were combined.

Significant Newman-Keuls values $(p<.01)$ were obtained for comparisons of failure condition (periods of increasing failure) $1 / 7$ vs all other conditions. Significance was also obtained for success conditions $1 / 7,6 / 7$, and $7 / 7$ compared with all other success conditions. Comparisons between failure and success induction for comparable periods were significant $(p<.01)$ for failure/success conditions $6 / 7$ and for condition $7 / 7$. The results are-presented in graphic form in Fig. 1.

We would be led to conclude that initial ratings of information quality tend to be moderately low; however, they increase quickly and remain generally constant with further increasing success or failure. The exception to this pattern is the further increase of perceived information quality when success reaches rather high levels. This perception of further increased quality produces the only differences between failure and success conditions. 


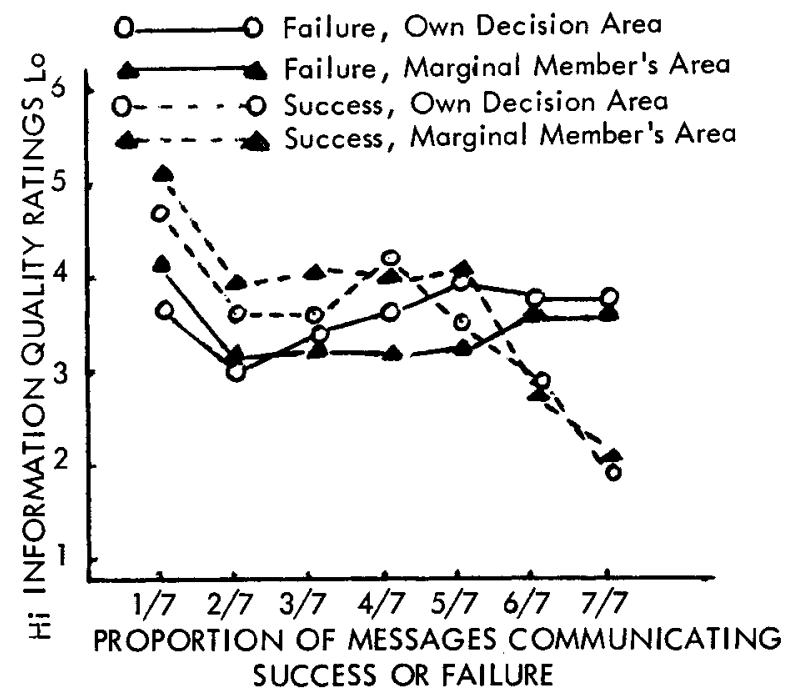

Fig. 1. Subjective estimates of information quality for own and marginal member's decision areas under conditions of experimentally-induced success and failure.

Discussion. One might argue that the ratings for information quality generally (except for the success condition when proportions of success messages reach $6 / 7$ and $7 / 7$ levels) remain constant and that the initial drop in perceived information quality between periods of failure or success proportions $1 / 7$ and $2 / 7$ are due to a beginning effect, or due to a lacking quantity of information (after only $1 / 2 \mathrm{~h}$ of play and seven informative messages) with which quality could be sufficiently associated. However, such an interpretation is not warranted, since data obtained in initial periods of previous runs of the experimental game when information load (quantity of information per unit time without success or failure components) was varied did not indicate such an effect.
Consequently, we would interpret this result as an outcome of low failure-success conditions with the associated stress levels proposed by Driver \& Streufert (1966) and Schroder et al (1967). It is this same effect that produced low attribution of responsibility levels to own and opposing team's decisions for the initial success and failure periods in the data reported by Streufert \& Streufert (1968). In this light, the results for periods with success and failure proportions $6 / 7$ and $7 / 7$ are particularly interesting. At success levels where Streufert \& Streufert report Ss taking increasing credit for their success, but where Ss who are failing do not take more (or less) credit for failure levels, Ss also perceive information as being of higher quality. It appears that high success levels have a specific evaluative effect which tends to color all perceptions in a favorable direction. It is interesting that failure induction does not produce the opposite result, as one might have predicted from the Schroder et al (1967) theory. Apparently success at high levels produces considerably more perceptual stress (in terms of that theory) than equivalent levels of failure. Based on the data of Streufert \& Streufert (1968) and the results reported here, further research on perceptual effect of high failure vs success levels seems indicated.

\section{REFERENCES}

ATTNEAVE, F. Applications of information theory to psychology. New York: Holt, 1959.

DRIVER, M. J., \& STREUFERT, S. Group composition, input load and group information processing. Purdue University: Institute for Research in the Behavioral, Economic and Management Sciences. Institute Paper 142, 1966.

SCHRODER, H. M., DRIVER, M. J., \& STREUFERT, S. Human information processing. New York: Holt, Rinehart \& Winston, 1967.

STREUFERT, S., KLIGER, S. C., CASTORE, C. H., \& DRIVER, M. J. A tactical and negotiation game for the analysis and decision integration across decision areas. Psychol. Rep., 1967, 20, 155-157.

STREUFERT, S., \& STREUFERT, S. C. The effect of conceptual structure, failure and success on attribution of causality and interpersonal attitudes. Purdue University: ONR Technical Report, 1968.

\section{NOTE}

1. Research support from the Office of Naval Research, Group Psychology Branch, is gratefully acknowledged. 